\title{
A New Class of Model Glycolipids: Synthesis, Characterization, and Interaction with Lectins
}

\author{
TAFFY J. WILLIAMS, ${ }^{1}$ NIKE R. PLESSAS, AND IRWIN J. GOLDSTEIN \\ Department of Biological Chemistry, The University of Michigan, Ann Arbor, Michigan 48109
}

AND

\section{JÖRGEN LÖNNGREN}

\begin{abstract}
Arrhenius Laboratory, Department of Organic Chemistry, University of Stockholm, S-10691 Stockholm, Sweden
\end{abstract}
Received December 28, 1978; revised January 29, 1979

\begin{abstract}
A method is described for preparing model glycolipids by linking aldobionic acids to an alkylamine through an amide bond. 'l'hese compounds may be rapidly prepared in large quantities. The glycolipids precipitate specifically with lectins. Precipitation occurs at glycolipid concentrations just above their critical micelle concentration.
\end{abstract}

Although lectin-reactive molecules in biomembranes are generally glycoproteins $(1,2)$, lectins also bind glycolipids (3-9). For a detailed study of lectin-glycolipid interaction we required substances of defined structure. Because isolation of naturally occurring glycolipids is time consuming and only small quantities are generally obtained pure, we synthesized these compounds. In this paper we report the synthesis, characterization, and some biological applications of a new class of model glycolipids which can be readily prepared in high yield as pure crystalline solids. A preliminary communication has already appeared (10).

\section{MATERIALS AND METHODS}

Materials. N-Phenyl-1-naphthylamine, ninhydrin, diphenylamine, $n$-octylamine, $n$-decylamine, $n$-undecylamine, $n$-dodecylamine, $n$-tetradecylamine, and $N, N^{\prime}$-dicyelohexylcarbodiimide (DCC) ${ }^{2}$ were obtained

' To whom requests for reprints should be sent.

2 Abbreviations used: DCC, $N, N^{\prime}$-dicyclohexylcarbodiimide; $\mathrm{RCA}_{1}$, castor bean lectin; $\mathrm{CMC}$, critical micelle concentration; salt/ $P$; buffer, $0.01 \mathrm{M}$ phosphate (pH 7.2), $0.5 \mathrm{M} \mathrm{NaCl}, 0.1 \mathrm{mM} \mathrm{MnCl}_{2}$, and $0.1 \mathrm{~mm}$ $\mathrm{CaCl}_{2}$; Con A, concanavalin A; PBS, phosphate buffered saline; Ac, acetyl; Manp, mannopyranoside; Galp, galactopyranoside; Glep, glucopyranoside. from the Aldrich Chemical Company (Milwaukee, Wis.). Methyl $\alpha$-D-mannopyranoside, methyl $\alpha$-D-galactopyranoside, melibiose, lactose, maltose, cellobiose, and gentiobiose were purchased from Pfanstiehl Laboratories, Inc. (Waukegan, Ill.). n-Hexadecylamine and $n$-tridecylamine were obtained from Eastman Kodak Company (Rochester, N. Y.). n-Octadecylamine was obtained from Koch-Light Laboratories, Ltd. (Colnbrook, Buck, England). Amberlite cation-exchange resin IR-120 C.P. was obtained from the Mallinkrodt Chemical Company (St. Louis, Mo.). Precoated silica gel G-60 tle plates were obtained from Brinkmann Instruments, Inc. (Westbury, N. Y.). Concanavalin A was prepared by the method of Williams et al. (11). Bandeiraea simplicifolia (BS I) lectin was isolated by the method of Murphy and Goldstein (12). Castor bean lectin $\left(\mathrm{RCA}_{1}\right)$ was a generous gift of Dr. Marilyn Etzer, University of California, Davis.

$N$-Dodecylmelibionamide. Melibiose was oxidized to potassium melibionate (13) followed by conversion to the free acid by treatment with Amberlite IR-120 $\left(\mathrm{H}^{+}\right)$. The aqueous solution of the free acid was dried in vacuo at $40^{\circ} \mathrm{C}$. Melibiono-1,5-lactone was formed by concentrating and drying melibionic acid by repeated evaporation from methanol and ethanol (14). Melibiono1,5-lactone ( $1 \mathrm{~g}, 2.8 \mathrm{mmol})$ was dissolved in methanol $(10 \mathrm{ml})$ by gentle heating, $n$-dodecylamine $(0.6 \mathrm{~g}, 3.2$ mmol) was added, and the reaction mixture was stirred overnight at room temperature. The precipitate which formed was filtered, washed with cold methanol, and air dried. Repeated recrystallization from methanol gave $N$-dodecylmelibionamide as a crystalline white 
solid (yield, $70 \% ; \mathrm{mp} 155-156^{\circ} \mathrm{C}$ ). It gave a single spot $\left(R_{f}, 0.30\right)$ on tlc (1-butanol:acetic acid:diethyl ether:water, 9:6:3:1) upon spraying with acidic diphenylamine (10). Anal. Caled for $\mathrm{C}_{24} \mathrm{H}_{47} \mathrm{NO}_{11}$ : C, 54.80; H, 9.08; N, 2.66. Found: C, 54.86; H, 9.14; N, 2.57. Preparation of other model glycolipids followed the same reaction scheme. The products, melting points, and elemental analyses are listed in Table I. The crystallization solvent for all synthetic glycolipids except the $N$-alkylmaltobionamides was methanol; the maltobionamides were crystallized from ethanol.

Determination of critical micelle concentration (CMC). CMC determinations were carried out on an Aminco-Bowman fluorimeter at $23^{\circ} \mathrm{C}$ using a fluorescent probe ( $N$-phenyl-1-naphthylamine). The $N$-phenyl-1naphthylamine was excited at $360 \mathrm{~nm}$ and the emission recorded at $425 \mathrm{~nm}$. The fluorescence change, plotted against glycolipid concentration, was extrapolated to the concentration at which fluorescence reached a minimum value, defined as the critical micelle concentration.

Precipitin reactions. A modification of the precipitin reaction described by So and Goldstein (15) was employed. Increasing quantities of glycolipid dissolved in salt $/ P_{\mathrm{j}}$ buffer $(0.01 \mathrm{M}$ phosphate, $\mathrm{pH} 7.2 ; 0.5 \mathrm{M}$ $\mathrm{NaCl} ; 0.1 \mathrm{mM} \mathrm{MnCl}_{2}$, and $0.1 \mathrm{mM} \mathrm{CaCl}_{2}$ ) were added to tubes containing buffer and lectin $(=60 \mu \mathrm{g})$ in a total volume of $0.5 \mathrm{ml}$. 'Tubes were incubated at $25^{\circ} \mathrm{C}$ for $48 \mathrm{~h}$, centrifuged, and washed with salt $/ P_{\mathrm{i}}$. The washed precipitates were dissolved in $0.05 \mathrm{M} \mathrm{NaOH}$ and protein was determined by a semimicro Lowry procedure (16). Sugar inhibition of the precipitin reaction was conducted by adding inereasing amounts of carbohydrate hapten to tubes containing lectin. The

TABLE I

Properties of Synthetic Glycolipids

\begin{tabular}{|c|c|c|c|c|c|c|c|c|c|}
\hline \multirow[b]{3}{*}{ Compound } & \multirow{3}{*}{$\begin{array}{c}\mathrm{mp} \\
\left({ }^{\circ} \mathrm{C}\right)\end{array}$} & \multicolumn{6}{|c|}{ Analyses } & \multirow{3}{*}{$\begin{array}{c}\text { Yield } \\
\%\end{array}$} & \multirow[b]{3}{*}{$\mathrm{CMC}$ in $\mathrm{H}_{2} \mathrm{O}$} \\
\hline & & \multicolumn{3}{|c|}{ \% Calculated } & \multicolumn{3}{|c|}{$\%$ Found } & & \\
\hline & & $\mathrm{C}$ & $\mathbf{H}$ & $\mathrm{N}$ & $\mathrm{C}$ & $\mathrm{H}$ & $\mathrm{N}$ & & \\
\hline$N$-Octyllactobionamide & $130-132$ & 51.16 & 8.37 & 2.98 & 51.24 & 8.38 & 3.05 & 86 & \\
\hline$N$-Decyllactobionamide & $128-129$ & 53.10 & 8.71 & 2.82 & 53.19 & 8.73 & 2.68 & 75 & $3.2(1600)^{a}$ \\
\hline$N$-Undecyllactobionamide & $149-150$ & 54.00 & 8.87 & 2.74 & 53.94 & 8.82 & 2.70 & 86 & \\
\hline$N$-Dodecyllactobionamide & $143-144$ & 54.80 & 9.08 & 2.66 & 54.54 & 8.76 & 2.53 & 90 & $0.285(150)$ \\
\hline$N$-Tridecyllactobionamide & $150-151$ & 55.64 & 9.15 & 2.60 & 55.78 & 9.27 & 2.58 & 100 & \\
\hline$N$-Tetradecyllactobionamide & $138-139$ & 56.30 & 9.28 & 2.53 & 56.08 & 9.32 & 2.41 & 90 & $0.0312(17.3)$ \\
\hline$N$-Hexadecyllactobionamide & $133-135$ & 57.80 & 9.53 & 2.40 & 57.64 & 9.50 & 2.32 & 90 & $\alpha^{b}$ \\
\hline$N$-Octylmaltobionamide & $116-117$ & 51.16 & 8.37 & 2.98 & 51.12 & 8.39 & 2.90 & 71 & \\
\hline$N$-Decylmaltobionamide & $119-120$ & 53.10 & 8.71 & 2.82 & 53.22 & 8.72 & 2.94 & 73 & $2.41(1200)$ \\
\hline$N$-Undecylmaltobionamide & $122-123$ & 54.00 & 8.87 & 2.74 & 53.91 & 8.76 & 2.68 & 74 & $0.88(450)$ \\
\hline$N$-Dodecylmaltobionamide & $120-121$ & 54.80 & 9.08 & 2.66 & 54.80 & 9.04 & 2.68 & 75 & $0.228(119.9)$ \\
\hline$N$-Tridecylmaltobionamide & $122-123$ & 55.64 & 9.15 & 2.60 & 55.53 & 9.19 & 2.57 & 74 & $0.074(40)$ \\
\hline$N$-Tetradecylmaltobionamide & $119-120$ & 56.30 & 9.28 & 2.53 & 56.46 & 9.35 & 2.52 & 80 & $0.032(17.6)$ \\
\hline$N$-Hexadecylmaltobionamide & $119-120$ & 57.80 & 9.53 & 2.40 & 57.64 & 9.45 & 2.40 & 89 & $\alpha^{b}$ \\
\hline$N$-Octylmelibionamide & $162-164$ & 51.16 & 8.37 & 2.98 & 50.96 & 8.35 & 3.02 & 93 & \\
\hline$N$-Decylmelibionamide & $160-162$ & 53.10 & 8.71 & 2.82 & 52.98 & 8.74 & 2.82 & 89 & $3.01(1500)$ \\
\hline$N$-Undecylmelibionamide & $157-158$ & 54.00 & 8.87 & 2.74 & 53.89 & 8.01 & 2.64 & 38 & $0.989(520)$ \\
\hline$N$-Dodecylmelibionamide & $155-156$ & 54.80 & 9.08 & 2.66 & 54.86 & 9.14 & 2.57 & 69 & $0.209(110)$ \\
\hline$N$-Tridecylmelibionamide & $152-154$ & 55.64 & 9.15 & 2.60 & 55.52 & 9.04 & 2.52 & 50 & $0.074(40)$ \\
\hline$N$-Tetradecylmelibionamide & $144-151$ & 56.30 & 9.28 & 2.53 & 56.14 & 9.33 & 2.58 & 98 & $0.030(16.6)$ \\
\hline$N$-Hexadecylmelibionamide & $148-150$ & 57.80 & 9.53 & 2.40 & 57.76 & 9.55 & 2.49 & 94 & $\alpha^{b}$ \\
\hline$N$-Tetradecylcellobionamide & $112-114$ & 56.30 & 9.28 & 2.53 & 56.28 & 9.27 & 2.47 & 100 & \\
\hline$N$-Hexadecylcellobionamide & $105-107$ & 57.80 & 9.53 & 2.40 & 57.53 & 9.42 & 2.36 & 100 & \\
\hline$N$-Decylgentiobionamide & $146-148$ & 53.10 & 8.71 & 2.82 & 52.60 & 8.64 & 2.76 & 100 & \\
\hline$N$-Dodecylgentiobionamide & $141-143$ & 54.80 & 9.08 & 2.66 & 54.63 & 8.91 & 2.64 & 95 & \\
\hline$N$-Tetradecylgentiobionamide & $144-146$ & 56.30 & 9.28 & 2.53 & 56.23 & 9.40 & 2.54 & 96 & \\
\hline$N$-Hexadecylgentiobionamide & $132-134$ & 57.80 & 9.53 & 2.40 & 57.94 & 9.65 & 2.48 & 95 & \\
\hline
\end{tabular}

${ }^{a}$ Values represent $\mathrm{mm}$ concentration with $\mu \mathrm{g} / \mathrm{ml}$ indicated in parentheses.

${ }^{b} \mathrm{CMC}$ was too low $(<2 \mu \mathrm{g} / \mathrm{ml})$ to be determined by the fluorescence method. 
precipitin reaction was initiated by addition of glycolipid at a final concentration which would precipitate maximal quantities of protein.

\section{RESULTS AND DISCUSSION}

Synthesis of the compounds in Table I follows a reaction scheme (Fig. 1) similar to that described for $N$-dodecylmelibionamide and $N$-dodecyllactobionamide (10). Initially, DCC was added to catalyze the formation of the aldobionamides. Subsequently it was discovered that amide formation proceeds via the aldobionolactone, formation of which is catalyzed by DCC. Lactone formation also may be effected by heating in vacuo and/or dissolution in organic solvents. In the present study, lactone formation was achieved by evaporating the lactubionic acid to dryness several times from ethanol or methanol in vacuo at $50^{\circ} \mathrm{C}$. Comparison of the carbon- $13 \mathrm{nmr}$ spectra of free acid and lactone revealed the presence of carbonyl carbon atoms with a chemical shift at about $180.0 \mathrm{ppm}$ with respect to trimethylsilane for the free aldobionic acid, and a resonance doubling and a shift toward trimethylsilane in the case of lactone carbonyl carbon atoms with peaks at 175.3 and $174.9 \mathrm{ppm}$. Addition of DCC is advisable when reaction mixtures contain mainly the free aldobionic acid and alkylamine. However, carbodimide may be omitted if aldobionolactone is used as reactant.

Occasionally, the aldobionamides appeared as a gel during recrystallization but repeated recrystallizations from methanol or ethanol provided an analytically pure, crystalline product. The $N$-alkyllactobionamides and
$N$-alkylmaltobionamides generally formed crystalline products readily whereas other glycolipids often formed gels. Purity of the glycolipids was readily monitored by thin layer chromatography. When spray reagents were used, the glycolipids were ninhydrin and aldose positive only after hydrolysis (10). Further characterization by ir spectroscopy yielded the characteristic amide I $\left(1655 \mathrm{~cm}^{-1}\right)$ and amide $11\left(1550 \mathrm{~cm}^{-1}\right)$ bands. Elemental analysis also confirmed the assigned structures.

Preparation of aqueous solution of the glycolipids usually required heating and sonication. The solubility of the substances in aqueous solution was affected by both the alkyl chain length and the nature of the carbohydrate head groups. At $1 \mathrm{mg} / \mathrm{ml}$, the alkyllactobionamides, cellobionamides, and gentobionamides (all containing $\beta$-Dglycosidic linkages) with alkyl chain lengths of 12 or more carbon atoms generally precipitated from aqueous solution on standing. In fact, the longer the alkyl chain, the more readily the glycolipids separated from solution. Chromatographically pure cellobionamides and gentiobionamides frequently formed gels and very viscous solutions.

In aqueous solution the synthetic glycolipids, like all surfactants, form micelles as detected by fluorescent enhancement of $N$-phenyl-1-naphthylamine which partitions very favorably into the detergent micelles. The quantum yield of the naphthylamine is increased in the presence of a hydrophobic substance (17). Figure 2 shows the enhancement of fluorescence observed in the presence of increasing quantities of glyco-
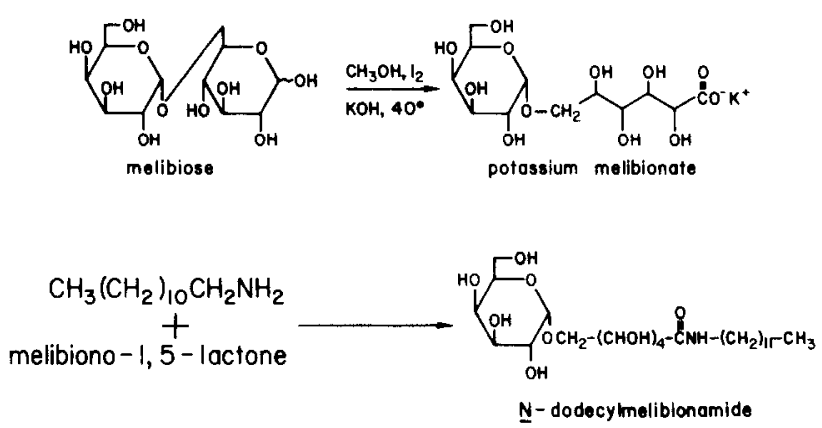

FIG. 1. Reaction scheme for preparation of $N$-dodecylmelibionamide. 


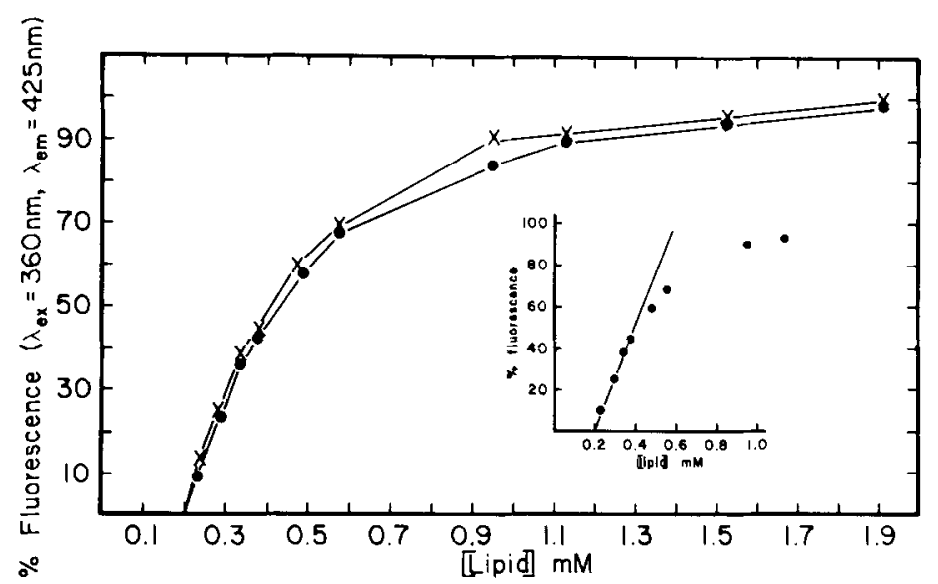

FIG. 2. Dependence of fluorescence of $N$-phenyl-1-naphthylamine on the concentration of glycolipid. (×) $N$-dodecylmelibionamide; (O) $N$-dodecylmaltobionamide. Inset represents extrapolation to $0 \%$ fluorescence.

lipid. Values of the CMC determined by this method (Table I) exhibited a logarithmic relationship with the number of carbon atoms in the alkyl chain. The least-squares fit of these data (Fig. 3) allows the formulation of a relationship which describes the free energy of micelle formation (18) in accordance with the equation $\Delta G=-R T \ln C M C$. The equations in Table II can be used to predict the $\Delta G$ of micelle formation for any glycolipid in a particular series by substituting the number of carbon atoms in the alkyl chain carbons for $n_{\mathrm{c}}$. Values of $3300-3500$

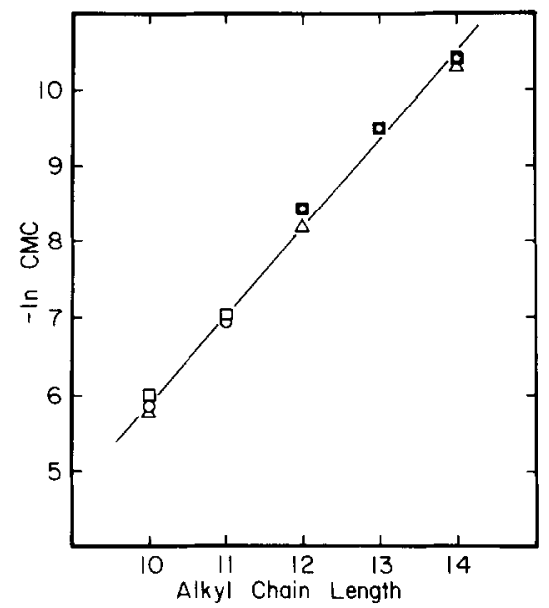

FIG. 3. Dependence of ln CMC on alkyl chain length. CMC values determined in distilled water. (O) $N$-alkylmelibionamides; $(\triangle) N$-alkylactobionamides; (口) $N$-alkylmaltobionamides. cal $/ \mathrm{mol}$ (Table II) were obtained for the contribution of the polar head group and are indicative of a rather strong interaction with the solvent. The $-680 \mathrm{cal} / \mathrm{mol}$ contribution to the free energy of micelle formation implies that from 6-7 carbons must be in the alkyl chain before $\Delta G$ becomes favorable for micelle formation. As detected by the similar curves in Fig. 3 and equations in Table II, CMC values are independent of the nature of the sugar moiety and of the nature and anomeric configuration of the glycosidic linkage.

Micelle formation by the synthetic glycolipids results in structures containing multiple carbohydrate groups on the surface and alkyl chains concentrated in the interior region of the micelle. The synthetic glycolipids when present as micelles precipitate with lectins. Quantitative precipitin curves of coneanavalin A (Con A) (Fig. 4), $\mathrm{B}_{4}$ isolectin from B. simplicifolia seeds (BS I) (Fig. 5), and $\mathrm{RCA}_{\mathrm{I}}$ (Fig. 6) were obtained with several glycolipids. In all three cases, precipitation occurs at the CMC (see Table III) and the lectin-glycolipid interactions were specific, in that a lectin precipitates only that glycolipid containing a carbohydrate with which it interacts. Since the CMC is governed by the number of carbon atoms in the alkyl chain, the quantity of glycolipid required for precipitation depends on the chain length. Comparisons of the point at which precipitation first occurred for the 
TABLE II

$\Delta G$ of Micelle Formation ${ }^{a}$

$N$-Alkylmelibionamide

$$
\Delta G=3516( \pm 394)-698( \pm 30) n_{\mathrm{c}}(\mathrm{cal} / \mathrm{mol})
$$

$N$-Alkylmaltobionamide

$$
\Delta G=3000( \pm 259)-661( \pm 21) n_{\mathrm{c}}(\mathrm{cal} / \mathrm{mol})
$$

$N$-Alkyllactobionamide

$$
\Delta G=3433( \pm 124)-687( \pm 11) n_{c}(\mathrm{cal} / \mathrm{mol})
$$

${ }^{a}$ Equations are obtained by a least-squares fit to the data in Fig. 3 according to the equation $\Delta G=-R T$ ln CMC. The slope of the graph is equal to - In CMC/alkyl carbon and the $y$-intercept $\left(n_{\mathrm{c}}=0\right)$ is related to the $\Delta G$ of solubilization of the polar head group (18).

reactions of the $N$-alkylmaltobionamides with Con $\mathrm{A}$, or reaction of $N$-alkylmelibionamides with the $\mathrm{BS} I$ lectin revealed that, as expected, 10-fold less glycolipid was required for each two-carbon increase in the alkyl chain length.

The incomplete precipitation of Con $\mathrm{A}$ by $N$-decylmaltobionamide and the failure of the Bandeiraea simplicifolia isolectins to

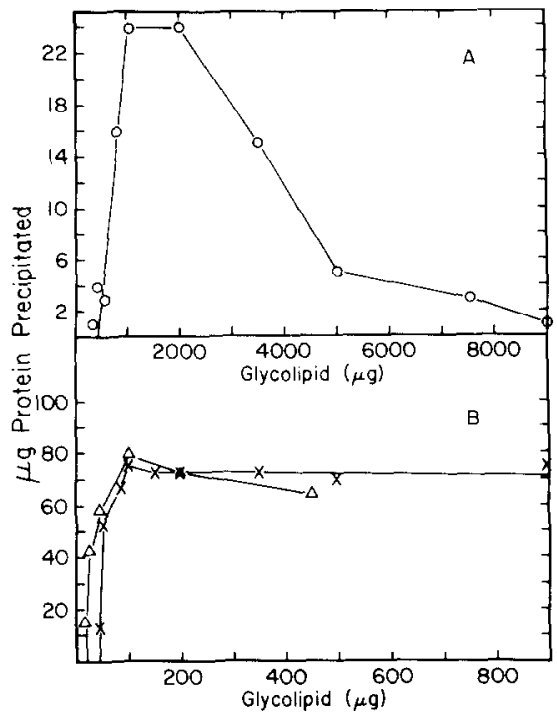

FIG. 4. Quantitative precipitin curves of $N$-alkylmaltobionamides with con A. Buffer consisted of PBS ( $/ 20.5, \mathrm{pH}$ 7.2). (A) (O) $N$-decylmaltobionamides; (B) ( $\times$ ) N-dodecylmaltobionamide; and ( $\triangle) N$-tetradecylmaltobionamide.

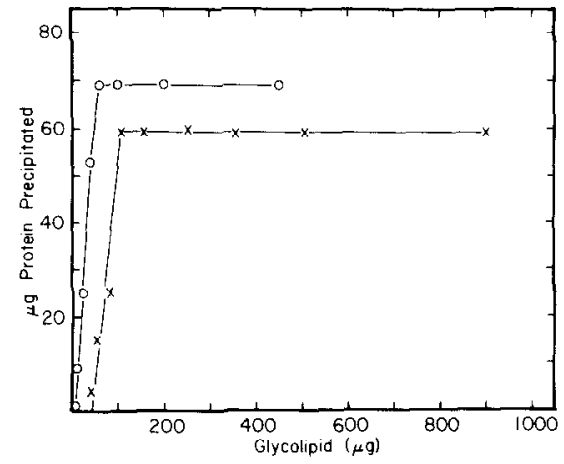

FIG. 5. Quantitative precipitin curves of $N$-alkylmelibionamides with BS I lectin. Buffer consisted of PBS ( $\Gamma / 20.5, \mathrm{pH} 7.2)$. ( $\times$ ) $N$-dodecylmelbionamide and $(\mathrm{O}) \mathrm{N}$-tetradecylmelibionamide.

precipitate $N$-decylmelibionamide are due to inhibition of precipitation by soluble, monomeric glycolipid molecules. At concentrations above the CMC a glycolipid monomer equal in concentration to the $\mathrm{CMC}$ is in solution. These monomeric glycolipids may act as competitive inhibitors in the same manner as mono- and oligosaccharides. The CMC values (in PBS buffer, Table III), for $N$-decylmaltobionamide and $N$-decylmelibionamide were determined to be $850 \mu \mathrm{g} / \mathrm{ml}$, high enough to inhibit or abolish the precipitation with concanavalin $A$ and the $B$. simplicifolia- $B_{4}$ isolectin, respectively. Figure 7 illustrates the manner in which $N$-decylmelibionamide inhibits precipitation of guaran and $B_{4}$ isolectin from $B$. simplicifolia seeds. On a molar basis, the glycolipid and methyl $\alpha$-Dgalactopyranoside are equally potent as inhibitors. Thus, the concentration of monomeric $N$-decylmelibionamide was sufficient

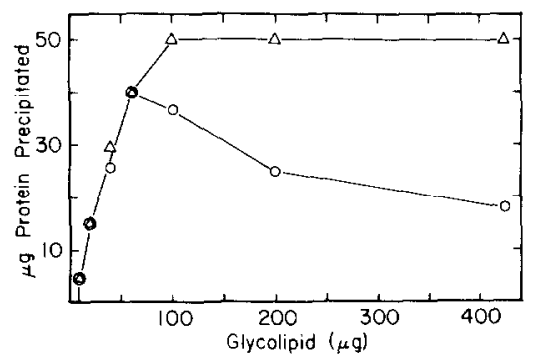

FIG. 6. Quantitative precipitin curves of $N$-tetradecylmelibionamide $(O)$ and $N$-tetradecylactobionamide $(\triangle)$ with $\mathrm{RCA}_{1}$. Buffer consisted of PBS ( $\left./ 20.5, \mathrm{pH} 7.2\right)$. 
TABLE III

GLYCOLIPID-LECTIN INTERACTION

\begin{tabular}{lclc}
\hline \multicolumn{1}{c}{ Glycolipid } & $\begin{array}{c}\text { Glycolipid } \\
\text { concentration at point } \\
\text { of precipitation }(\mu \mathrm{g} / \mathrm{ml})\end{array}$ & \multicolumn{1}{c}{$\begin{array}{c}\text { Lectin } \\
\text { (carbohydrate- } \\
\text { binding specificity) }\end{array}$} & $\begin{array}{c}\mathrm{CMC}^{a} \\
(\mu \mathrm{g} / \mathrm{ml})\end{array}$ \\
\hline$N$-Decylmaltobionamide & 900 & Concanavalin A & 850 \\
$N$-Dodecylmaltobionamide & 74 & $(\alpha$-D-Manp $>\alpha$-D-Glc $p \gg \alpha$-D-GleNAc $p)$ & 75 \\
$N$-tetradecylmaltobionamide & 12 & & 5.5 \\
$N$-Decylmelibionamide & $-{ }^{\circ}$ & Bandeiraea simplicifolia B $_{4}$-isolectin & 850 \\
$N$-Dodecylmelibionamide & 80 & $(\alpha$-D-Gal $p)$ & 75 \\
$N$-Tetradecylmelibionamide & 5 & & 5.5 \\
$N$-Tetradecylmelibionamide & 12 & RCA $_{1}(\beta$-D-Gal $p \simeq \alpha$-D-Gal $p)$ & 5.5 \\
$N$-Tetradecyllactobionamide & 12 & & 5.5 \\
\hline
\end{tabular}

${ }^{a}$ Critical micelle concentration in PBS buffer ( $\Gamma / 20.5, \mathrm{pH}$ 7.2).

${ }^{b}$ Precipitation did not occur due to high CMC.

to completely inhibit precipitate formation at the concentration at which micelles of this glycolipid first form.

Inhibition of lectin-glycolipid precipitation by monosaccharides further demonstrates the specificity of the precipitation reaction as well as the ability of glycolipids to compete with monosaccharides for the carbohydrate binding site. In Fig. 7, the competitive inhibitor, methyl- $\alpha$-D-galactopyranoside, inhibits formation of the BS I lectin- $N$-dodecylmelibionamide complex at $0.5 \mathrm{~mm}$ whereas $10 \mathrm{~mm}$ methyl- $\alpha$-D-mannopyranoside failed to inhibit. Methyl- $\alpha$-D-

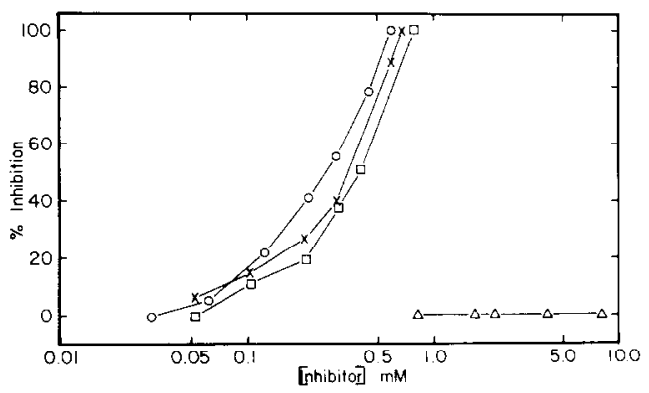

FIG. 7. Inhibition of BS I lectin-guaran and $N$-dodecylmelibionamide precipitation by low molecular weight ligands. Buffer consisted of PBS ( $\Gamma / 20.5$, $\mathrm{pH} 7.2)$; BS I ( $50 \mu \mathrm{g} /$ tube), and guaran $(7.5 \mu \mathrm{g} /$ tube $)$ inhibited by $N$-decylmelibionamide (O) or methyl$\alpha$-D-Galp (X). BS I (50 $\mu \mathrm{g} /$ tube) and $N$-dodecylmelibionamide $(150 \mu \mathrm{g} / \mathrm{tube})$ inhibited by methyl$\alpha$-D-Galp $(\square)$ or methyl- $\alpha$-D-Man $p(\triangle)$. mannopyranoside inhibits Con A-glycolipid complex formation of $0.5 \mathrm{~mm}$ while $10 \mathrm{~mm}$ methyl- $\alpha$-D-galactopyranoside failed to inhibit (Fig. 8).

Finally, $N$-alkylaldobionamides in concentrations related to their CMC lyse erythrocytes. For example, $N$-decyl-, $N$-dodecyl-, and $N$-tetradecyl-aldobionamides cause lysis in the concentration ranges $800 / 1000,30-40$, and 3-4 $\mu \mathrm{g} / \mathrm{ml}$, respectively. This observation is consistent with the detergent property of these substances.

\section{ACKNOWI,FGMFNTS}

This study was supported by Public Health Service Grants AM-10171, CA-20424, and CA 1F32-CA-06110.

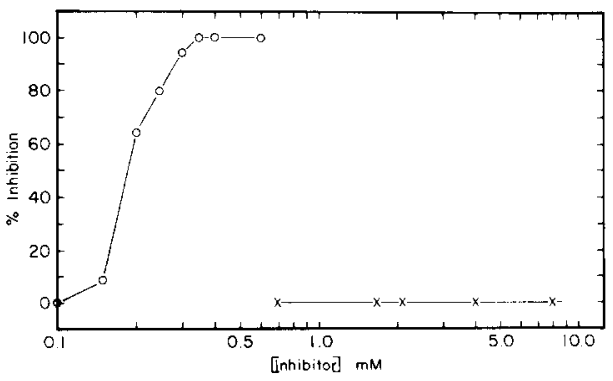

FIG. 8. Inhibition of Con A-N-dodecylmaltobionamide precipitation by low molecular weight ligands. Buffer consisted of PBS ( $\Gamma / 20.5, \mathrm{pH} 7.2$ ); Con A (50 $\mu \mathrm{g} /$ tube) and $N$-dodecylmaltobionamide ( $100 \mu \mathrm{g} /$ tube) inhibited by methyl- $\alpha$-D-Manp (O) or methyl- $\alpha$-DGal $p(\times)$. 
Part of this work was done under Naval Medical Research and Development Command, Research Work Unit No. MR04101010146. We gratefully acknowledge the assistance of Dr. Robert Loughlin of the Procter and Gamble Company in determining the critical micelle concentration of the synthetic glycolipids.

\section{REFERENCES}

1. Goldstein, I. J., ANd Hayes, C. E. (1978) Advan. Carbohyd. Chem. Brochem. 35, 127-340.

2. Lis, H., And Sharon, N. (1973) Annu. Rev. Biochem. 42, 541-574.

3. Boldt, D. H., Speckart, S. F., Richards, R. L., And Alving, C. R. (1977) Biochem. Biophys. Res. Commun. 74, 208-214.

4. Deleers, M., Poss, A., and Ruysschaert, J. M. (1976) Biochem. Biophys. Res. Commun. $72,709-713$.

5. Read, B. D., Demel, R. A., Wiegandt, H., AND VAN DEENEN, L. L. M. (1970) Biochim. Biophys. Acta 470, 325-330.

6. ReDwood, W. R., AND PolefkA, T. G. (1976) Biochim. Biophys. Acta 455, 631-643.
7. Guratolo, W., Shipley, G. G., Small, D. M., Sears, B., AND Neuringer, L. S. (1977) J. Amer. Chem. Soc. 99, 6771-6772.

8. Maget-Dana, R., Roche, A., and Monsigny, M. (1977) FEBS Lett. 79, 305-309.

9. WATANABE, K., AND HaKomoRI, S. (1973) FEBS Lett. 37, 317-320.

10. Williams, T. J., Plessas, N., and Goldstein, I. J. (1978) Carbohyd. Res. 67, C1-C3.

11. Williams, T. J., Goldstein, I. H., and Shafer, J. A. (1978) J. Biol. Chem. 253, 8533-8537.

12. Murphy, L. A., AND Goldstein, I. J. (1977) J. Biol. Chem. 252, 4739-4742.

13. Moore, S., AND Link, K. P. (1940) J. Biol. Chem. 133, 293-311.

14. Isbell, H. S., AND Frish, H. L. (1963) Methods Carbohyd. Chem. 2, 16-18.

15. So, L. L., AND Goldstein, I. J. (1967) J. Biol. Chem. 242, 1617-1622.

16. Mage, R., AND Dray, S. (1965) J. Immunol. 95, 525-535.

17. RADDA, G. K. (1971) Biochem. J. 122, 385-396.

18. TANFORD, C. (1973) The Hydrophobic Effect, Wiley, New York. 